\title{
Transposable elements generate population-specific insertional patterns and allelic variation in genes of wild emmer wheat (Triticum turgidum ssp. dicoccoides)
}

\author{
Katherine Domb, Danielle Keidar, Beery Yaakov, Vadim Khasdan and Khalil Kashkush*
}

\begin{abstract}
Background: Natural populations of the tetraploid wild emmer wheat (genome AABB) were previously shown to demonstrate eco-geographically structured genetic and epigenetic diversity. Transposable elements (TEs) might make up a significant part of the genetic and epigenetic variation between individuals and populations because they comprise over $80 \%$ of the wild emmer wheat genome. In this study, we performed detailed analyses to assess the dynamics of transposable elements in 50 accessions of wild emmer wheat collected from 5 geographically isolated sites. The analyses included: the copy number variation of TEs among accessions in the five populations, population-unique insertional patterns, and the impact of population-unique/specific TE insertions on structure and expression of genes.

Results: We assessed the copy numbers of 12 TE families using real-time quantitative PCR, and found significant copy number variation (CNV) in the 50 wild emmer wheat accessions, in a population-specific manner. In some cases, the CNV difference reached up to 6-fold. However, the CNV was TE-specific, namely some TE families showed higher copy numbers in one or more populations, and other TE families showed lower copy numbers in the same population(s). Furthermore, we assessed the insertional patterns of 6 TE families using transposon display (TD), and observed significant population-specific insertional patterns. The polymorphism levels of TE-insertional patterns reached $92 \%$ among all wild emmer wheat accessions, in some cases. In addition, we observed population-specific/unique TE insertions, some of which were located within or close to protein-coding genes, creating allelic variations in a population-specific manner. We also showed that those genes are differentially expressed in wild emmer wheat.
\end{abstract}

Conclusions: For the first time, this study shows that TEs proliferate in wild emmer wheat in a population-specific manner, creating new alleles of genes, which contribute to the divergent evolution of homeologous genes from the $A$ and $B$ subgenomes.

Keywords: Copy number variation, Dicoccoides, Emmer wheat, Genetic variation, Transposable elements, TE dynamics

\section{Background}

Wild emmer wheat, Triticum turgidum ssp. dicoccoides, is an allotetraploid annual self-pollinating grass species formed 300,000-500,000 years ago, by hybridization between two diploid species harboring $\mathrm{AA}$ and $\mathrm{BB}$ genomes $[1,2]$. Based on molecular evidence, it was proposed that the allopolyploidization event that led to the creation of wild emmer wheat occurred in Mt. Hermon and upper Jordan Valley area [3-5]. During its evolution,

\footnotetext{
*Correspondence: kashkush@bgu.ac.il

Department of Life Sciences, Ben-Gurion University, 84105 Beer-Sheva, Israel
}

wild emmer wheat spread within the region, surviving several rapid climate changes. The last of which, known as "the big freeze", was characterized by temperature drops and dry conditions, occurred $\sim 11,000$ years ago $[6,7]$. Paleobotanical findings from this period suggest wild emmer wheat might have been distributed along the "Levantine Corridor", the narrow strip between southeastern Turkey and the Sinai peninsula, at least in its central-southern part [8].

The present-day wild emmer wheat is distributed in a patchy manner throughout the middle east Fertile 
Crescent, in various environmental conditions differing in soil types, mean annual temperatures, rainfall levels and other abiotic and biotic conditions [4].

In Israel, wild emmer wheat can be found between Mt. Hermon in the north and Mt. Amasa (Judea desert) in the south, as over 20 isolated or semi-isolated populations. The ecogeographical conditions (rainfall, temperature, humidity) do not vary dramatically among populations, except for the marginal populations, e.g. the temperatures frequently dropping below $0{ }^{\circ} \mathrm{C}$ in the winter in $\mathrm{Mt}$. Hermon, and very low rainfall levels in Mt. Amasa [4, 9]. Wild emmer wheat populations from Israel were tested for phenotypic differences, and high variability was found in traits such as vegetative weight, seed weight, flowering time, pathogen resistance [10], drought tolerance [11] and other parameters, many of them of high agronomic importance. Several studies that have investigated the genetic structure and differentiation of wild emmer wheat on both the macro- and micro-scale level were published using limited numbers of genetic markers [12-14]. Genetic variation within and between wild emmer wheat populations was tested previously using genetic markers allowing the examination of a limited number of sites $[4,12,14,15]$, and possible adaptive genetic differentiation was found.

The relatively large genome of wild emmer wheat $(\sim 12$ Gbp) contains $80-90 \%$ transposable elements (TEs) from both main classes [16-18]: class I (retrotransposons or RNA elements) and class II (DNA elements). Retrotransposons are mobile elements that proliferate by creating exact copies of themselves via RNA intermediates. They are subdivided into retrotransposons with long terminal direct repeats (LTRs) at their termini, and non-LTR retrotransposons. DNA elements have terminal inverted repeats, and are further subdivided based on their TIR sequence, transposase sequence and target site duplication. Both TE classes include autonomous elements encoding all the enzymes required for transposition, and non-autonomous elements that rely on enzymes encoded by autonomous elements [19]. The autonomous LTR retrotransposons have given rise to non-autonomous LARDs (Large Retrotransposon Derivatives) and TRIM (Terminal Repeats in Miniature). SINE (Small Interspersed Nuclear Elements) retrotransposons, unlike other non-autonomous TEs, are not derivatives of autonomous elements, and have likely originated from retrotransposition of PolIII transcripts. TIRs DNA elements have given rise to multiple non-autonomous elements of various sizes, including the smallest (dozens to hundreds of bp in length) DNA elements designated MITEs (Miniature Inverted Repeat Transposable Elements) possessing TIRs and a short non-coding internal sequence [19]. TE proliferation and elimination are two major contributors to change in the genome sizes of flowering plants [20]. In addition to shaping the size of the genome, TEs may affect gene expression in various ways: (1) insertions into exons usually lead to loss of function or alter the gene product, (2) insertion into introns can cause new alternative splicing [21], and (3) insertion into regulatory sequences upstream or downstream to a gene may lead to either upregulation or downregulation, depending on the role of a particular regulatory sequence [22]. Furthermore, as a natural target for various epigenetic silencing mechanisms, TEs induce formation of heterochromatic islands, which may lead to downregulation of genes located within flanking regions $[22,23]$.

In this study, we aimed to elucidate the dynamics of TEs in natural habitats of wild emmer wheat accessions. We analyzed in detail $12 \mathrm{TE}$ families representing both TE classes in 50 accessions collected from five geographically isolates sites (populations). The analyses included: (1) Assessment of the variation in TE copy numbers in emmer wheat accessions; (2) Assessment of the insertional patterns of TEs within and between the five wild emmer wheat populations; (3) Identification of population-specific/unique TE insertions within proteincoding genes and assessment of the allelic variation caused by TEs; and (4) Assessment of the expression profile of genes that harbor polymorphic TE insertions in wild emmer wheat. To this end, we have observed significant copy number variations of TEs within and between wild emmer wheat populations. In addition, for the first time, we report on TE-derived allelic variation in protein-coding genes in a population-specific/unique matter in natural populations of emmer wheat. The impact of TEs on genetic diversity and evolution of wild emmer wheat is discussed.

\section{Methods}

\section{Plant material}

Wild emmer wheat (T. turgidum ssp. dicoccoides) accessions used in this study were gathered from five geographically isolated sites (populations) in Israel, and were provided to us by Israeli stock centers, as following: accessions from Mount Hermon, Tabgha and Jaba collecting sites, are available in the Wild Cereals gene bank (WCGB) - Institute of Evolution, University of Haifa; Mount Hermon, while accessions from Amiad and Mount Amasa are available in the Lieberman Germplasm Bank, Institute for Cereal Crops Improvement, Tel-Aviv University. For details on the exact locations of the collection sites and eco-geographical conditions, see Additional file 1: Table S1 in our recent publication [24]. Next, 10-20 accessions from each population were grown in a greenhouse under common garden conditions $\left(25^{\circ} \mathrm{C}, 16 \mathrm{~h} / 8 \mathrm{~h}\right.$ long day). Leaf material was harvested approximately 4 weeks post germination for DNA extraction using the DNeasy plant mini kit (Qiagen), and total RNA extraction using TriReagent (Sigma-Aldrich). 


\section{Assessment of TE copy numbers using real-time quantitative PCR (qPCR)}

The copy number variation of 8 DNA elements (class II) and 4 retrotransposons (class I) in 50 wild emmer wheat accessions was determined by real-time qPCR. Details on TE families analyzed in this study are shown in Table 1. TE-specific primers (Additional file 1: Table S1) were designed using Primer Express v3.0 software (Applied Biosystems). Quantitative PCR reactions using genomic DNA templates isolated from wild emmer wheat accessions were performed by a 7500 Fast RealTime PCR system and analyzed using the 7500 version 2.0.5 software (Applied Biosystems). Each reaction contained: $7.5 \mu \mathrm{l}$ KAPA SYBR FAST qPCR Master Mix, $0.3 \mu \mathrm{l}$ ROX Low (KAPA BIOSYSTEMS), $1 \mu \mathrm{l}$ forward

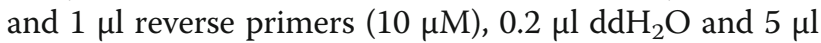
template genomic DNA $(0.25 \mathrm{ng} / \mu \mathrm{l})$. The PCR conditions for these reactions were: $95^{\circ} \mathrm{C}$ for $3 \mathrm{~min}$, repeat $\left(95^{\circ} \mathrm{C}\right.$ for $1 \mathrm{~min}, 60^{\circ} \mathrm{C}$ for $1 \mathrm{~min}$ ) 40 times; following the last cycle, a melting curve was performed in order to validate product specificity. For each DNA sample (accession) a qPCR reaction was performed using three replicates. Data for each sample was received as $\mathrm{C}_{\mathrm{T}}$ - threshold cycle of the PCR amplification, normalized to the $\mathrm{C}_{\mathrm{T}}$ of VRN1, a known single copy number gene [25] used as an endogenous control [26-28]. A comparative $2^{-\Delta \Delta C T}$ method was then used to determine the relative quantity (RQ) of the target in each sample by comparing the normalized target quantity in each sample to the normalized target quantity in the reference sample (A1) based on the following equation: $\Delta \Delta \mathrm{C}_{\mathrm{T}) \text { test sample }}=\left[\mathrm{C}_{\mathrm{T} \text { (target) }}-\mathrm{C}_{\mathrm{T} \text { (VRN1) }}\right]_{\text {(test sample) }}-$

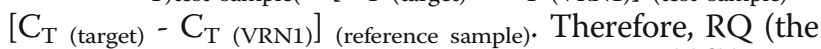
relative copy number $)=(2 \times \text { primer efficiency })^{-\Delta \Delta C T}$ [29].

Table 1 Transposable element families analyzed in this study

\begin{tabular}{lllll}
\hline Class $^{\text {a }}$ & Order $^{\text {b }}$ & Superfamily & Family & Size (bp) \\
\hline I & LTR & Gypsy & Fatima & 9997 \\
$\mid$ & LTR & Gypsy & Latidu & 13,068 \\
$\mid$ & LTR & Unknown & Veju & 2530 \\
$\|$ & Non-LTR & SINE & Au & 181 \\
$\|$ & TIR & Mutator & Apollo & 866 \\
$\|$ & TIR & CACTA & Balduin & 11,744 \\
$\|$ & TIR & Tc1/Mariner & Eos & 354 \\
$\|$ & TIR & Tc1/Mariner & Fortuna & 353 \\
$\|$ & TIR & Tc1/Mariner & Tantalos & 257 \\
$\|$ & TIR & Tc1/Mariner & Minos & 236 \\
$\|$ & TIR & Tc1/Mariner & Aison & 219 \\
\hline
\end{tabular}

I = class I- RNA elements, II = class II- DNA elements

b LTR- long terminal repeat retrotransposon, TIR- terminal inverted repeat

'Based on: TREP (http://botserv2.uzh.ch/kelldata/trep-db/index.html) and giri-repbase (http://www.girinst.org/repbase/update/browse.php). All the Tc1/ Mariners are Inverted-Repeat Transposable Elements (MITEs)
For miniature elements (MITEs and $A u$ ) absolute copy numbers were calculated, using absolute numbers of elements retrieved from the bread wheat genome draft [30]. QPCR was performed to assess the RQ of these elements in bread wheat (accession TAA01, cultivar Chinese Spring) and in a wild emmer wheat reference sample, then the RQs were normalized to their ploidy levels, as the tetraploid accession used as reference sample has two copies of VRN1 gene, while the hexaploid bread wheat has three copies of VRN1. Absolute numbers of each element were calculated in the reference sample by multiplying the ratio of its relative quantity to that of Triticum aestivum by the copy number $(\mathrm{CN})$ of $T$. aestivum retrieved from the bread wheat genome draft for each MITE using the MAK software [31]: $\left(\mathrm{RQ}_{\text {sample }} / \mathrm{RQ}_{\mathrm{TAA} 01}\right) \times \mathrm{Cnt}$, aestivum .

The resulting data was analyzed by using one-way analysis of variance (ANOVA); when a significant variation in average copy numbers of a TE family was detected by ANOVA, Tukey's post hoc test was performed $(P<0.05$ was set as the level of statistical significance). The statistical tests were performed using STATISTICA [32] software.

\section{Transposon display (TD)}

TD is a modification of the AFLP technique, allowing a genome-wide analysis of transposon insertion sites [33, 34]. The TD reaction was performed according to a previously published protocol [33]. Briefly, genomic DNA was treated with $M s e I$ restriction enzyme, and the restriction fragments were ligated to adaptors, which include an overhang complementary to the overhang produced by MseI. A preselective PCR reaction was performed using one primer complementary to the adaptor sequence and a second primer designed from the transposon sequence. Selective amplification was carried out with the addition of three arbitrary nucleotides at the 3 ' end of the adaptor primer and a ${ }^{32} \mathrm{P}$-labeled transposon primer. Here we have analyzed the insertional patterns of six Miniature Inverted-repeat Transposable Elements (MITEs) using a specific primer for each one of the MITE families (details on primers and adaptor sequences are presented in Additional file 1: Table S2). The selective PCR products were separated on denaturing $6 \%$ polyacrylamide gel. The gel was then removed on Whatman ${ }^{\oplus}$ paper, dried and exposed to X-ray film for $8 \mathrm{~h}$, up to a week (depending on the $\beta$-emission intensity). Each TD band represents an insertion site that was clearly visible on the $\mathrm{X}$-ray film. A matrix was built based on the presence (1) or absence (0) of a band in each accession for further analyses. The insertional polymorphism levels were calculated for each TE family in each population as the ratio between the number of polymorphic bands (bands present in some accessions and absent 
from other accessions of a population) and the total number of bands present in the population. Finally, TD bands were extracted from polyacrylamide gels, reamplified using the same PCR conditions as in the TD selective PCR reaction, and sequenced, as previously described [24].

\section{Computer-assisted analysis}

Annotation and retrieving of TE sequences and their flanking sequences was performed using the genomic DNA, cDNA, coding sequence (CDS) and non-coding RNA (ncRNA) databases of different grass genomes taken from EnsemblPlants (http://plants.ensembl.org) and expressed sequence tag (EST) databases taken from PlantGDB (http://www.plantgdb.org/prj/ESTCluster/). The annotation was performed using BLAST+ standalone version 2.2.3 with an $E$-value of $10^{-10}$ [35].

\section{Phylogenetic analysis}

Primer6 software [36], version 6.1 .6 was used to construct hierarchical agglomerative clustering phylogenetic trees according the insertional polymorphism of each MITE family based on TD patterns, as described previously [24]. Primer6 software performed hierarchical agglomerative clustering analysis of each matrix with Bray-Curtis similarity and used the similarity profile (SIMPROF) test on each node to assess the statistical significance of the phylogenetic trees. SIMPROF calculates a mean profile by randomizing each variable's values and re-calculating the profile. The $p i$ statistic is calculated as the deviation of the actual resemblance profile of the resemblance matrix with the mean profile. This is compared with the deviation of further randomly-generated profiles to test for significance. In phylogenetic trees, black lines indicate statistically significant clusters $(p<0.05)$, and red lines indicate insignificant clusters.

\section{Site-specific PCR}

Site-specific PCR primers (Additional file 1: Table S3) for examination of single TE insertion sites were designed using Primer3 software (http://bioinfo.ut.ee/primer3-0.4.0/primer3/). PCR reactions were prepared using $13.2 \mu \mathrm{l}$ of Ultra Pure Water (HyLabs), $2 \mu \mathrm{l}$ of $10 \times$ Taq DNA polymerase buffer C (EURx), $0.8 \mu \mathrm{l}$ of $25 \mathrm{mM}$ $\mathrm{MgCl}_{2}$ (EURx), $0.8 \mu \mathrm{l}$ of $2.5 \mathrm{mM}$ dNTPs, $0.2 \mu \mathrm{l}$ of Taq DNA polymerase $(5 \mathrm{U} / \mu \mathrm{l}, \mathrm{EURx}), 1 \mu \mathrm{l}$ of each sitespecific primer $(50 \mathrm{ng} / \mu \mathrm{l})$ and $1 \mu \mathrm{l}$ of genomic DNA $(50 \mathrm{ng} / \mu \mathrm{l})$ of each wild emmer wheat accession. The PCR conditions for these reactions were: $94^{\circ} \mathrm{C}$ for $3 \mathrm{~min}$, repeat $\left(94^{\circ} \mathrm{C}\right.$ for $1 \mathrm{~min}, 57^{\circ} \mathrm{C}$ for $1 \mathrm{~min}, 72^{\circ} \mathrm{C}$ for $\left.1 \mathrm{~min}\right) 30$ times and $72^{\circ} \mathrm{C}$ for $3 \mathrm{~min} .10 \mu \mathrm{l}$ of PCR products were run on $1.5 \%$ agarose gels and visualized with ethidium bromide (Amresco). The expected product sizes were determined against a DNA size standard (100 bp ladder, $\mathrm{SMOBiO})$.

\section{Gene expression analysis using real-time RT-PCR}

Complementary DNA (cDNA) for gene expression analysis was prepared using $5 \times$ All-In-One RT MasterMix $\left(\mathrm{ABM}^{\circ}\right)$, in $20 \mu \mathrm{l}$ reaction volumes. Each reaction contained $4 \mu \mathrm{l}$ of MasterMix and $2 \mu \mathrm{g}$ of RNA in $16 \mu \mathrm{l}$ of Ultra Pure Water (HyLabs). The reactions were incubated at $42{ }^{\circ} \mathrm{C}$ for $15 \mathrm{~min}$. Each cDNA sample was tested using a site-specific PCR reaction with primers from two adjacent exons of the Actin gene, giving different amplification products for CDNA and genomic DNA and no DNA contamination was detected. The expression levels of five genes were tested by real-time RT-PCR. Primers specific to the cDNA sequence of each gene (Additional file 1: Table S4) were designed using Primer Express v2.0 software. For genes containing multiple exons, one of the primers was complementary to an exon-exon junction in order to make the reaction less sensitive to possible genomic DNA contamination of RNA samples. RT-PCR reactions were performed by a 7500 Fast RealTime PCR system and analyzed using the 7500 version 2.0.5 software (Applied Biosystems). Each reaction contained: $7.5 \mu \mathrm{l}$ KAPA SYBR FAST qPCR Master Mix, $0.3 \mu \mathrm{l}$ ROX Low (KAPA BIOSYSTEMS), $1 \mu \mathrm{l}$ forward

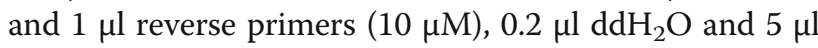
template cDNA. The PCR conditions for these reactions were: $95^{\circ} \mathrm{C}$ for $3 \mathrm{~min}$, repeat $\left(95^{\circ} \mathrm{C}\right.$ for $1 \mathrm{~min}, 60^{\circ} \mathrm{C}$ for $1 \mathrm{~min}) 40$ times; in order to validate product specificity, a melting curve was performed and demonstrated a single specific product for each primer pair (see an example in Additional file 2: Figure S9).

Primer efficiency was tested by performing RT-PCR reactions with each primer pair on serial dilutions of template cDNA mix and producing a standard curve. Efficiency $=\left[\left(10^{-1 / y}\right)-1\right] \times 100 \%$, where $y$ is the standard curve slope. Based on the standard curve, we chose the 50-fold dilution of cDNA to be used as template in RTPCR reactions for gene expression analysis.

RT-PCR data was analyzed as described above using comparative $2^{-\Delta \Delta C T}$ method, using Actin expression levels as endogenous control and one arbitrarily chosen accession as reference sample.

\section{Results}

Copy number variation of selected DNA and RNA elements in wild emmer wheat populations

Because over $80 \%$ of the wheat genome is made up by TEs, they might have a prominent impact on the genetic diversity in wild emmer wheat populations. Thus, in this study, we have evaluated the copy numbers of several TE families representing different classes and different superfamilies, in each one of the 50 accessions. To this 
end, the copy numbers of four class I families (Fatima, Latidu, Veju and $A u$ ) and eight class II (Apollo, Balduin, Eos, Fortuna, Tantalos, Minos, Aison and Oleus) families (Table 1) were measured in all accessions. We used realtime quantitative PCR to assess the copy number of each one of the $12 \mathrm{TE}$ families in each one of the 50 accessions, using specific primers for each TE family (Additional file 1: Table S1). The quantity of each TE family amplified by qPCR was normalized to $V R N 1$, a gene with a single copy in each wheat genome [26-28], and then to one accession (A1 accession from Amiad population, see Additional file 2: Figures S1 and S2) that was arbitrarily chosen, and set as 1 in order to allow relative comparison among all accessions. For miniature TE families (MITEs and $A u$ ), absolute numbers were estimated using normalization to the copy number of each family in T. aestivum genome draft [30]. The copy numbers of long elements in wild emmer wheat accessions are presented here as relative quantities based on the qPCR analysis. Finally, for each one of the analyzed TE families, the average copy numbers in each one of the five populations were calculated separately (Figs. 1 and 2). The statistical significance of variation of average copy numbers among populations was analyzed by using one-way analysis of variance (ANOVA), followed by Tukey's post hoc test ( $p<0.05$ was considered statistically significant).

Copy numbers in each accession are shown in Additional file 2: Figure S1 (for DNA elements), and Additional file 2: Figure S2 (for retrotransposons). Note that standard deviation (SD) in all realtime qPCRs were calculated based on three replicates from each one of the accessions.

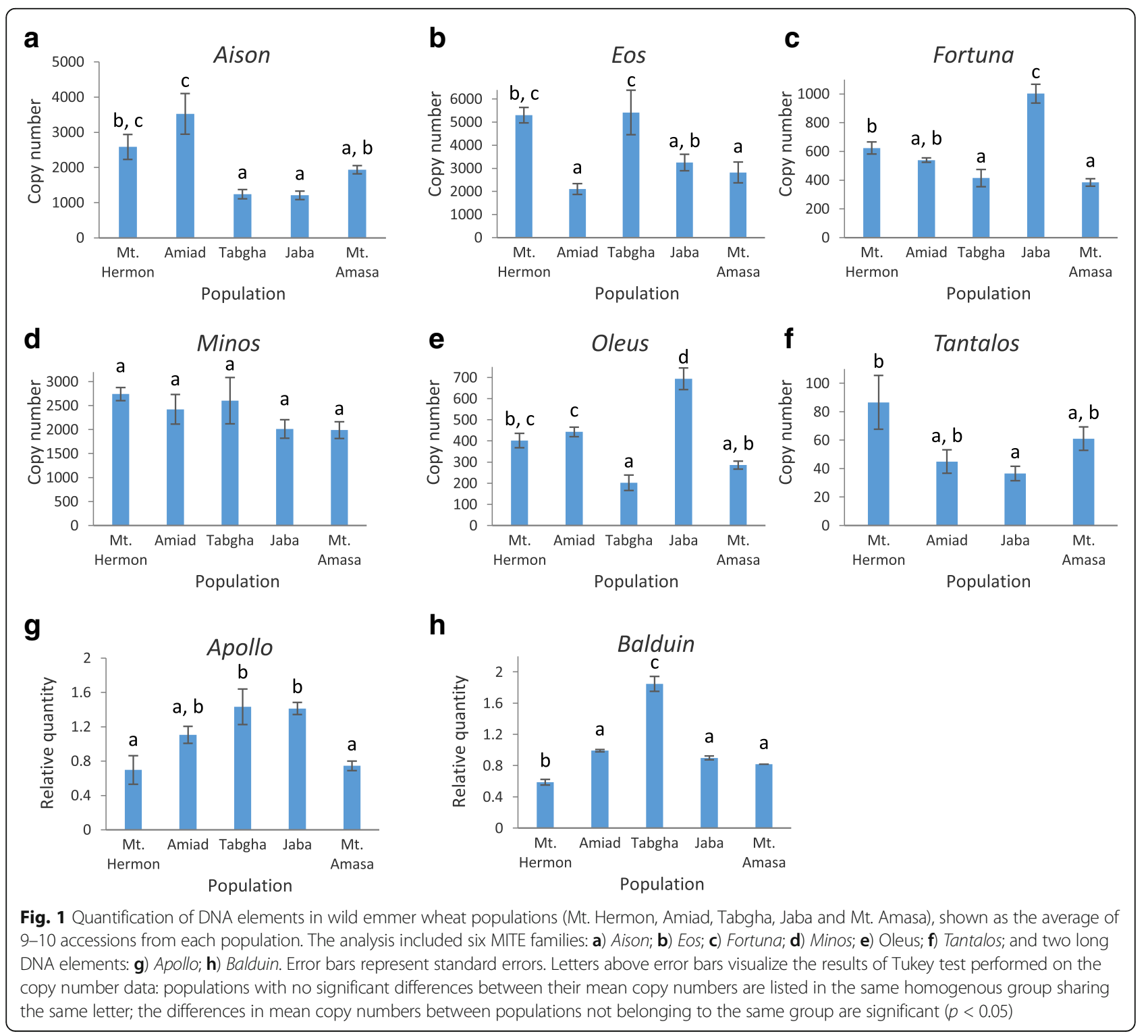



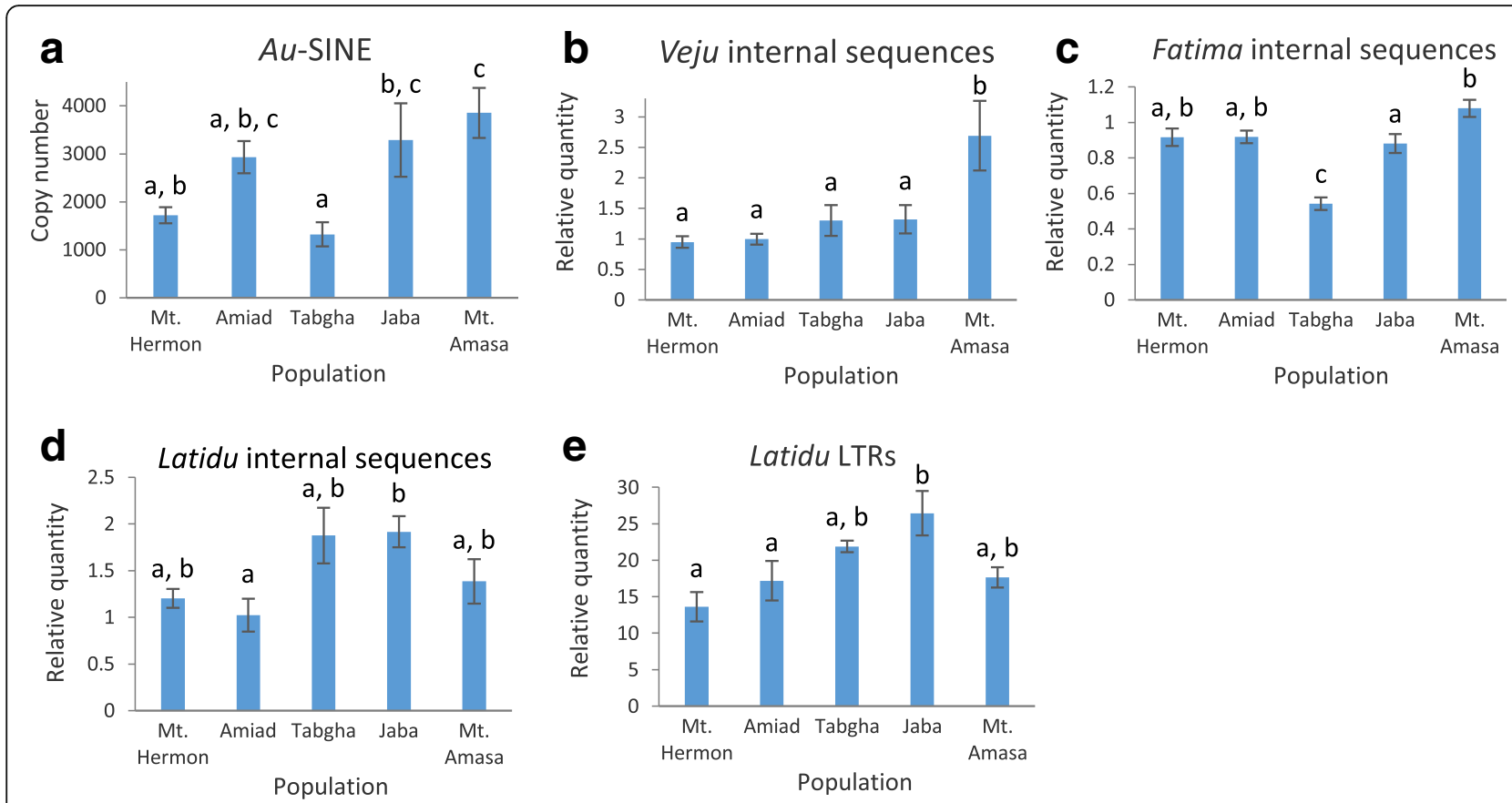

Fig. 2 Quantification of retrotransposons in wild emmer wheat populations (Mt. Hermon, Amiad, Tabgha, Jaba and Mt. Amasa), shown as the average of 5-10 accessions from each population. a) Miniature retrotransposon Au. LTR-retrotransposons: b) Veju, c) Fatima (internal sequence), d) Latidu (internal sequence), e) Latidu (LTR). Error bars represent standard errors. Letters above error bars visualize the results of Tukey test performed on the copy number data: populations with no significant differences between their mean copy numbers are listed in the same homogenous group sharing the same letter; the differences in mean copy numbers between populations not belonging to the same group are significant $(p<0.05)$

\section{Copy number variation of DNA elements (class II)}

Except for Minos, the five MITE families (Eos, Fortuna, Tantalos, Aison and Oleus) showed statistically significant $(\mathrm{p}<0.05)$ copy number variation among accessions of the 5 populations of emmer wheat (Fig. 1): (1) Aison showed the highest average copy number of 3528 insertions in accessions collected from Amiad population, significantly higher than in other populations (Fig. 1a), while accessions of Tabgha and Jaba populations showed the smallest average copy numbers of Aison, with 1224 and 1210 copies, respectively. In addition, Mt. Hermon and Mt. Amasa accessions showed intermediate average copy number of Aison. Furthermore, significant variation among accessions within each population was observed (Additional file 2: Figure S1a), ranging from close to 1.5fold differences between some accessions within $\mathrm{Mt}$. Amasa and Mt. Hermon populations and over 4.5-fold differences within Amiad population. (2) Eos showed the lowest average copy number of 2104 in accessions of the Amiad population (Fig. 1b), significantly lower than in accessions of other populations. The highest average copy numbers were observed in Mt. Hermon and Tabgha populations (5305 and 5417, respectively), and while the average copy numbers in these two populations were similar, the standard error demonstrates high internal variation in Tabgha accessions compared to Mt. Hermon. Jaba and Mt. Amasa accessions showed intermediate average copy numbers. The copy number differences within most populations ranged between 2fold to 4-fold (Additional file 2: Figure S1b). (3) Fortuna showed the lowest average copy number of 384 in accessions of Mt. Amasa, while the highest average copy number of 1003 was observed in Jaba (Fig. 1c). The average copy numbers in accessions of Tabgha were close to Mt. Amasa, in Mt. Hermon and Amiad higher average copy numbers were observed. In addition, no significant copy number variation was observed within accession of the Amiad population, while in other populations the greatest differences between accessions ranged between 2-fold (Mt. Hermon) and 6-fold (Tabgha) (Additional file 2: Figure S1c). (4) Minos average copy numbers were found to range between 2742 in Mt. Hermon and 1989 in Mt. Amasa (Fig. 1d), but no significant variation between populations was seen. The copy numbers of Minos were not uniform within populations, the highest copy number differences within populations ranged between 1.5-fold (in the Mt. Hermon population) and 2-fold (in the Tabgha population) (Additional file 2: Figure S1d). (5) The average copy numbers of Oleus ranged between 202 in accessions of Tabgha and 694 in accessions of Jaba. Oleus copy numbers in accessions of Mt. Amasa were close to those in Tabgha, while Mt. Hermon and Amiad show intermediate copy numbers of this element (Fig. 1e). Significant copy number variations 
between accessions in each population were observed (Additional file 2: Figure S1e), with over 6-fold differences between accessions of the Tabgha population. (6) Tantalos copy numbers, tested in 4 populations, were relatively low, ranging between 37 copies in Jaba and 87 in Mt. Hermon (Fig. 1f). Accessions of Amiad and Mt. Amasa showed intermediate copy numbers of 45 and 61, respectively. Significant variation within populations was observed, with the lowest being a 4-fold difference between Mt. Amasa accessions and the highest a 10-fold difference between Amiad accessions (Additional file 2: Figure S1f). The average copy numbers of two long DNA elements (Apollo and Balduin, see Table 1) were also found to be statistically significant among the 5 populations (Fig. 1g, h, respectively). For Apollo, the highest relative quantity was observed in accessions from Tabgha and Jaba populations, while the lowest relative quantity ( $\sim$-fold less) was observed in Mt. Hermon and Mt. Amasa populations. Furthermore, the observed relative quantity in each accession shows that the variation among accessions reaches up to 6-fold differences (Additional file 2: Figure S1 h). The highest average relative quantity of Balduin was observed in accessions of Tabgha $~ 3$-fold higher than in Mt. Hermon and 2-fold higher than in Amiad (Fig. 1h). In addition, the average relative quantity in Jaba and Mt. Amasa were close to those in Amiad. Furthermore, no significant variation was seen among accessions within each population indicating low level of Balduin activity in emmer wheat.

\section{Copy number variation of RNA elements (class I)}

Here we have measured the copy number or relative quantity of 4 retrotransposons (Au, Veju, Fatima and Latidu) representing different superfamilies (Table 1). As we have mentioned above, we were able to estimate the absolute copy number of $A u$ because of its short sequence (181 bp, Table 1) which can be retrieved from the genome draft accurately. The average copy numbers of $A u$ were significantly different among populations, ranged between 1321 in Tabgha and to 3853 in Mt. Amasa (Fig. 2a). In addition, a significant variation in copy number among accessions within each one of the five populations was observed (Additional file 2: Figure S2a), indicating high dynamics of $A u$ in wild emmer wheat. The relative quantities of three LTR retrotransposons (Veju, Fatima and Latidu) were measured by real-time qPCR using primers specific to the internal sequence that allow the amplification of intact and truncated elements in the genome. In addition, for further validation of the relative quantity, Latidu was quantified using primers designed specifically from the LTR sequence, in order to also estimate instances of solo-LTRs. Note that the relative quantities of both Latidu internal sequences and Latidu LTRs were normalized to the same reference sample in order to allow comparison between them. To this end, the relative quantity of Veju, a non-autonomous LTR retrotransposon, was observed in the 50 accessions of the 5 wild emmer wheat populations, and was found significantly different among accessions (Additional file 2: Figure S2b). The average relative quantity in each population was compared and displayed significant differences (Fig. 2b), while the highest average quantity was observed in Mt. Amasa, 2-fold higher than the average quantity in the Mt. Hermon and Amiad populations. Fatima is a long (approximately 10 kbp, Table 1) LTR retrotransposon, previously reported to be very abundant in the wheat genome [37]. The relative quantity of Fatima was measured in all 50 accessions and significant differences were found (Additional file 2: Figure S2c). Finally, the relative quantity of Latidu was measured in 26 accessions from 5 populations and significant differences were found (Additional file 2: Figure S2d). In addition, the average relative quantities of Latidu vary significantly between populations, while the highest quantities were observed in Tabgha and Jaba populations, and the lowest were observed in Amiad and Mt. Hermon (Fig. 2d). Note that similar patterns were obtained when the quantity of Latidu LTRs was tested (Fig. 2e, and Additional file 2: Figure S2e).

\section{Insertional patterns of MITEs in wild emmer wheat accessions}

The significant variation in copy numbers of most examined TEs observed in wild emmer wheat accessions hinted that proliferation of TEs might occur in a populationspecific manner. Thus, we have analyzed the insertional patterns in all accessions of the 5 populations using the Transposon Display (TD) technique. The TD analysis allowed detection of population- specific/unique transposon insertional patterns. In this analysis, we have focused on MITEs because they were previously reported to show high dynamics in wheat $[27,28,38]$. We have analyzed the insertional patterns of the six MITE families (Table 1) in 7-10 accessions of each population, using TD. Each lane in the TD pattern presents a subset of MITE/ flanking-containing sequences (Fig. 3), indicating specific insertion sites of a specific MITE family in one accession. For each MITE family, 70-115 insertions (overall 557 MITE insertions) were analyzed by TD (Table 2). Insertional polymorphism levels in each wild emmer wheat population were calculated for each one of the six MITE families based on the number of polymorphic insertions among accessions of each population (Table 2). Note that an insertion was considered polymorphic if it is absent in at least one accession. Of the 557 total MITE insertions, 400 were polymorphic, namely $78.8 \%$ of the insertions were polymorphic in all tested accessions of wild emmer wheat. This high level of polymorphism might indicate that MITEs might have retained their activity in natural 


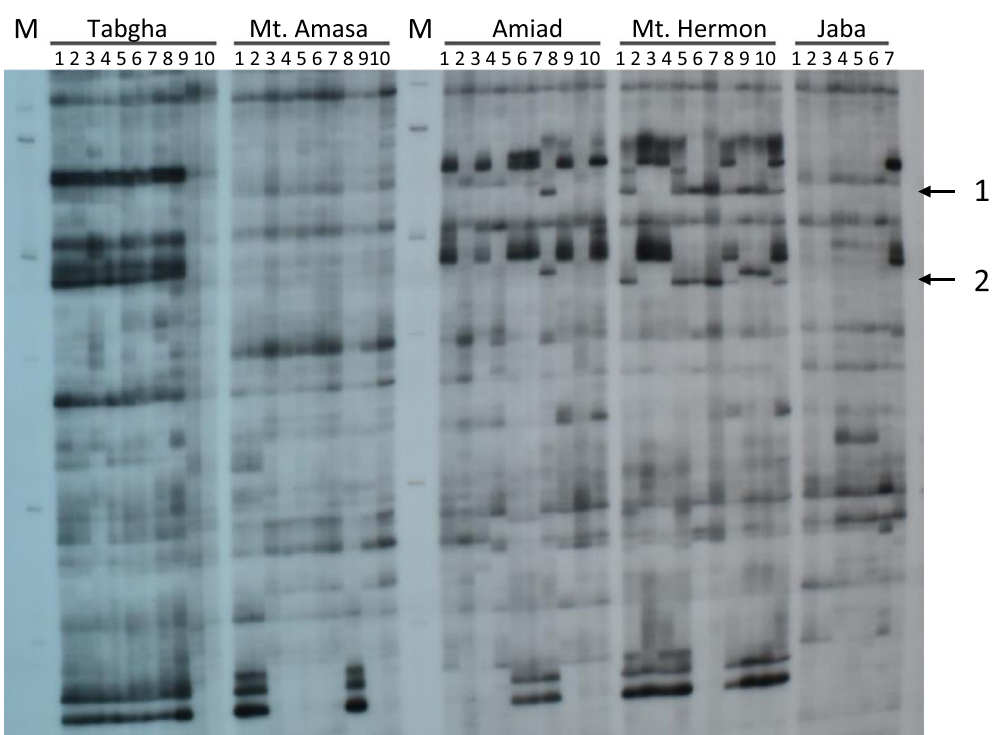

Fig. 3 TD gel visualizing insertional patterns of Aison (MITE) in 7-10 accessions of 5 wild emmer wheat populations using the Aison-specific primer and M-CTA (see Additional file 1: Table S2). Each lane represents one accession and each band represents a single insertion site. M denotes the size marker (100 bp). Examples of population-specific/unique bands are indicated by arrows and numbers: 1 - population-specific insertion (exists in Amiad and Mt. Hermon populations but not in others), 2 - population-unique insertion (exists only in Mt. Hermon)

Table 2 Insertional polymorphism levels of 6 MITEs in wild emmer wheat populations as observed in TD

\begin{tabular}{|c|c|c|c|c|c|c|c|}
\hline \multirow[t]{2}{*}{ TE family } & & \multicolumn{5}{|l|}{ Population $^{\text {b }}$} & \multirow[t]{2}{*}{ Total $^{c}$} \\
\hline & & Mt.Hermon & Amiad & Tabgha & Jaba & Mt.Amasa & \\
\hline \multirow[t]{3}{*}{$\overline{\text { Aison }}$} & Polymorphic bands & 50 & 62 & 57 & 45 & 25 & 92 \\
\hline & Total number of bands & 72 & 78 & 72 & 70 & 60 & 99 \\
\hline & Polymorphism level (\%) & 69.4 & 79.5 & 79.2 & 64.3 & 41.7 & 91.9 \\
\hline \multirow[t]{3}{*}{ EOS } & Polymorphic bands & 37 & 39 & 50 & 26 & 23 & 69 \\
\hline & Total number of bands & 75 & 75 & 79 & 66 & 68 & 92 \\
\hline & Polymorphism level (\%) & 49.3 & 52.0 & 63.3 & 39.4 & 33.8 & 75.0 \\
\hline \multirow[t]{3}{*}{ Fortuna } & Polymorphic bands & 52 & 51 & 58 & 54 & 41 & 61 \\
\hline & Total number of bands & 65 & 65 & 68 & 68 & 54 & 70 \\
\hline & Polymorphism level (\%) & 80.0 & 78.5 & 85.3 & 79.4 & 75.9 & 87.1 \\
\hline \multirow[t]{3}{*}{ Minos } & Polymorphic bands & 18 & 23 & 13 & 15 & 9 & 34 \\
\hline & Total number of bands & 81 & 83 & 76 & 80 & 79 & 88 \\
\hline & Polymorphism level (\%) & 22.2 & 27.7 & 17.1 & 18.8 & 11.4 & 38.6 \\
\hline \multirow[t]{3}{*}{ Oleus } & Polymorphic bands & 36 & 28 & 27 & 38 & 20 & 48 \\
\hline & Total number of bands & 81 & 80 & 79 & 85 & 76 & 92 \\
\hline & Polymorphism level (\%) & 44.4 & 35.0 & 34.2 & 44.7 & 26.3 & 52.2 \\
\hline \multirow[t]{3}{*}{ Tantalos } & Polymorphic bands & 56 & 48 & 63 & 70 & 43 & 96 \\
\hline & Total number of bands & 100 & 95 & 99 & 107 & 92 & 116 \\
\hline & Polymorphism level (\%) & 56.0 & 50.5 & 85.9 & 65.4 & 46.7 & 82.8 \\
\hline
\end{tabular}

${ }^{a}$ TD reactions were performed for 6 MITE families using: (1) two primer combinations, Aison-specific primer/M-CTA and Aison-specific primer/ M-CTC; (2) two primer combinations, Eos-specific primer/M-CTA and Eos-specific primer/M-CTG; (3) Fortuna-specific primer/M-CTA; (4) Minos-specific primer/M-CTA and Minos-specific primer/M-CTG; (5) Oleus-specific primer/M-CTA and Oleus-specific primer/M-CTG; (6) Tantalos-specific primer/M-CTA and Tantalos-specific primer/M-CTG. See Additional file 1: Table S2 for details on primer sequences

${ }^{\mathrm{b}}$ TD band was considered polymorphic when it was present/or absent in at least one accession. Total number of bands is the sum of polymorphic and monomorphic bands

'Based on the analysis of all 50 accessions together, indicating the overall level of polymorphism in the collection set 
populations of emmer wheat. The overall insertional polymorphism levels of MITEs ranged between 38.6\% (Minos) and $91.9 \%$ (Aison). The polymorphism levels of MITEs vary among populations, for example Aison polymorphism levels are between $79.5 \%$ in Amiad and $41.7 \%$ in Mt. Amasa, possibly indicating different activity levels in the different populations.

Phylogenetic trees generated by hierarchical agglomerative clustering were built based on the insertional patterns of the six MITE families and showed that accessions were significantly $(p<0.05)$ clustered based on their geographical location (Fig. 4 and Additional file 2: Figures S3-S7), indicating population-specific MITE proliferation in wild emmer wheat. The phylogenetic tree based on Minos insertional patterns (Fig. 3) showed that all accessions of Mt. Amasa and Mt. Hermon and most accessions of Tabgha significantly clustered according to their geographical location. The phylogenetic trees built based on the data of the rest of the tested MITE families (Eos, Aison, Fortuna, Oleus and Tantalos, Additional file 2: Figures S3-S7) demonstrated different degrees of significant populationspecific clustering and intra-population separation, possibly indicating different degrees of activity.

\section{Polymorphic MITE insertions into genes cause allelic variation in a population-specific/unique manner} Interestingly, 181 of the polymorphic insertions (17.9\% of the analyzed 557 MITE insertions) were considered population-specific insertions because they were absent in all accessions of at least one or more populations and present in at least one accession of each one of the other populations (for example see band \#1 in Fig. 3). In addition, 38 (6.8\%) insertions were found to be population-unique, namely, the insertion is present in one population only and absent in all accessions of the other populations (for example see band \#2 in Fig. 3).

In order to characterize in detail population-specific/ unique insertions, we have extracted 52 bands from polyacrylamide gels, reamplified them using the same conditions of the selective PCR reaction used in TD assay, and then sequenced them. The sequence of the 52 TD bands showed that all include MITE/flanking sequences. Annotations of the flanking sequences of the 52 revealed that most sequences (36 of the 52 ) hit noncoding sequences, while 6 hit known TEs, and the remaining 10 hit predicted protein-coding sequences (Table 3). This data showed that population-specific/ unique TE insertions might be located within wheat genes and might affect the structure (allelic variation) or the expression of the gene in different populations.

In order to focus on polymorphic MITE insertions within genes we have arbitrarily retrieved 60 MITE elements and their flanking sequences (100 bp from each side of the element) from the publicly available sequences of emmer wheat, which were inserted into known protein-coding genes, including those that were

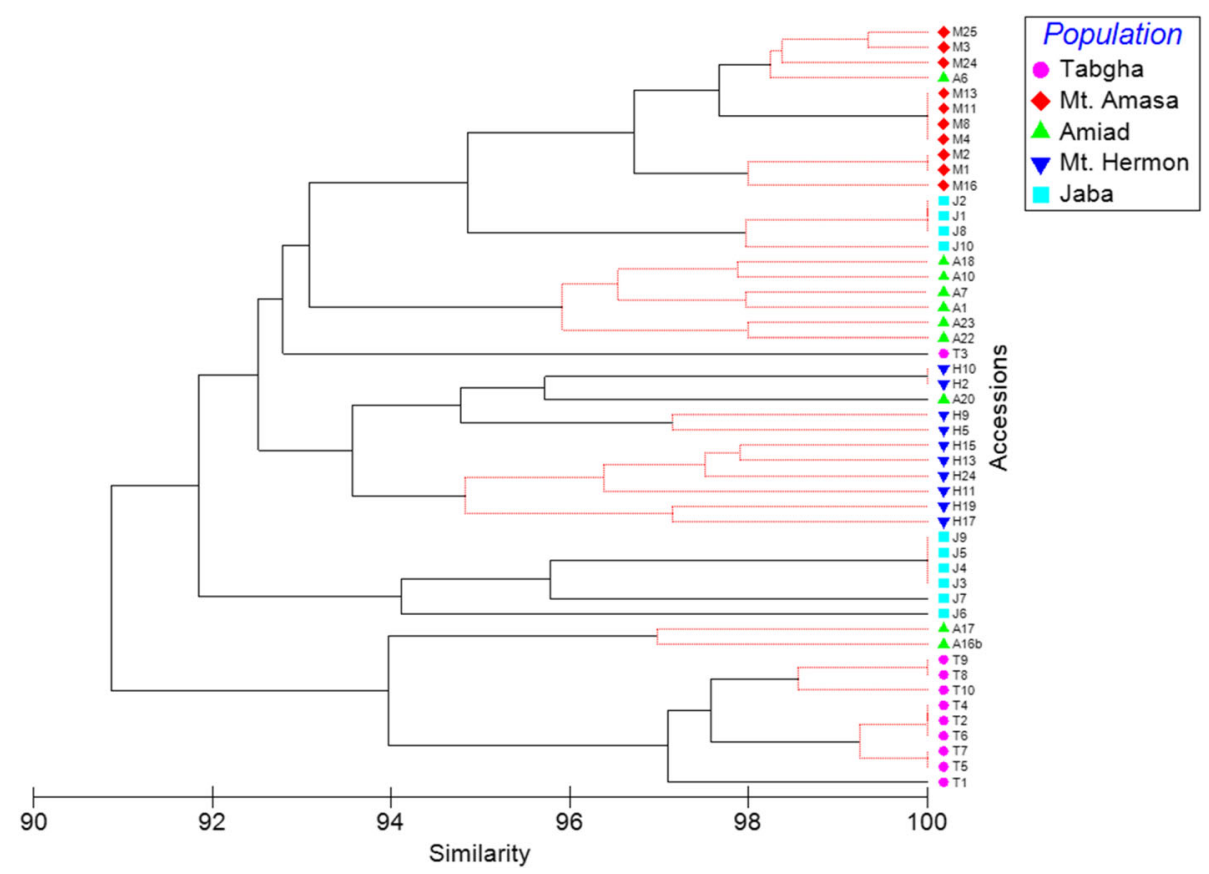

Fig. 4 Phylogenetic tree generated by hierarchical agglomerative clustering based on 88 TD bands of Minos in 50 accessions from 5 wild emmer wheat populations: Mt. Hermon, Amiad, Tabgha, Jaba and Mt. Amasa. The index (top right) shows the collection site of each accession. The black lines indicate significant separation, while red lines indicate insignificant separation. The level of similarity is indicated on the bottom 
Table 3 Detailed analysis of genes harboring polymorphic insertions of MITEs

\begin{tabular}{|c|c|c|c|c|c|c|c|c|c|}
\hline \multirow[t]{2}{*}{ Gene $^{a}$} & \multirow[t]{2}{*}{ Gene product ${ }^{b}$} & \multirow[t]{2}{*}{ TE family ${ }^{c}$} & \multirow[t]{2}{*}{ TE insertion location ${ }^{d}$} & \multicolumn{5}{|c|}{ Insertions in population ${ }^{\mathrm{e}}$} & \multirow[t]{2}{*}{ Gel image $^{f}$} \\
\hline & & & & $\mathrm{H}$ & A & $\mathrm{T}$ & J & M & \\
\hline TRIUR3_24471 & $\begin{array}{l}\text { a sterol-dependent membrane } \\
\text { protein, At3g47200-like }\end{array}$ & Aison & $\begin{array}{l}400 \text { bp upstream, } \\
\text { genome B }\end{array}$ & 2 & 0 & 0 & 0 & 0 & Fig. $6 a$ \\
\hline TRIUR3_29094 & integral membrane component & Aison & Intron 4, genome A & 0 & 1 & 2 & 0 & 0 & Fig. S8a \\
\hline Traes_2BS_2453C5E6B & $\begin{array}{l}\text { Response to oxidative stress; } \\
\text { peroxidase activity }\end{array}$ & Aison & Intron 3, genome B & 2 & 1 & 2 & 2 & 2 & Fig. S8b \\
\hline Traes_7BL_2E24532BD & RNA binding, ribosomal protein & Aison & Intron, genome B & 2 & 1 & 1 & 1 & 2 & Fig. S8c \\
\hline FJ640556.1 & $\begin{array}{l}\text { AIP2.2 - ABI3 (abscisic acid-insensitive } \\
\text { 3)-interacting protein }\end{array}$ & $A u$ & Intron 3, genome B & 2 & 1 & 1 & 1 & 2 & Fig. S8d \\
\hline Traes_1BL_DD7D021A7 & Ubiquitin-protein ligase & $A u$ & Intron 5 , genome B & 1 & 1 & 0 & 0 & 0 & Fig. S8e \\
\hline \multirow[t]{2}{*}{ TRIUR3_22200 } & \multirow{2}{*}{$\begin{array}{l}\text { ER membrane protein, transferring } \\
\text { acyl groups other than amino-acyl } \\
\text { groups, metabolic process }\end{array}$} & EOS & Intron 4, genome A & 2 & 1 & 2 & 1 & 1 & Fig. S8f \\
\hline & & Thalos & Intron 1, genome A & 2 & 2 & 1 & 1 & 2 & Fig. 6d \\
\hline Traes_4BS_AAE1439D4 & $\begin{array}{l}\text { Nuclear-localised, ATP binding, } \\
\text { transcription regulation }\end{array}$ & EOS & Exon (UTR), genome A & 2 & 1 & 0 & 1 & 2 & Fig. $6 c$ \\
\hline GU817319.1- locus tag - 2383A24.5 & $\begin{array}{l}\text { Predicted, homolog of Os01g0121600, } \\
\text { integral membrane component }\end{array}$ & Hades & $\begin{array}{l}960 \text { bp upstream, } \\
\text { genome B }\end{array}$ & 0 & 1 & 0 & 0 & 0 & Fig. $58 \mathrm{~g}$ \\
\hline Traes_3AS_94E185821 & Calcium ion binding protein & Minos & $\begin{array}{l}2 \text { bp downstream, } \\
\text { genome } A\end{array}$ & 2 & 1 & 1 & 2 & 2 & Fig. S8 h \\
\hline Traes_3AS_2755E639C & Uncharacterized protein & Minos & $\begin{array}{l}22 \text { bp upstream, } \\
\text { both genomes }\end{array}$ & 1 & 1 & 1 & 0 & 0 & Fig. S8i \\
\hline Traes_7AL_OD3EF0026 & Uncharacterized protein & Minos & $\begin{array}{l}\text { Exon } 2 \text { (UTR), } \\
\text { genome A }\end{array}$ & 0 & 1 & 1 & 0 & 0 & Fig. $6 b$ \\
\hline Traes_3B_5DEF2D3F1 & $\begin{array}{l}\text { Basic helix-loop-helix transcription } \\
\text { factor }\end{array}$ & Tantalos & Intron 3, genome B & 0 & 1 & 1 & 0 & 0 & Fig. S8j \\
\hline
\end{tabular}

${ }^{\mathrm{a} G e n e}$ ID in EnsembIPlants database, or GenBank accession in NCBI

${ }^{b}$ Protein product function, based on annotation found in NCBI (for known genes), or prediction from EmsemblPlants

${ }^{c}$ MITE associated with genes

${ }^{d}$ Position of the given TE insertion in relation to gene features (the number of intron or exon for insertions within genes, or the distance in base pairs from the first or the last exon for insertions upstream of downstream to genes), and the genome (A, B or both) in which the given insertion was detected

'The presence/absence of TE insertion within/close to a gene in a given population: 0 - empty site in all accessions, 1 - full site in some accessions, 2 - full site in all accessions

${ }^{\mathrm{f}}$ Figure or supplemental figure showing ssPCR gel image

detected in TD analysis. We then performed site specific PCR to test whether an accession included a specific MITE insertion (full site) or not (empty site), using specific primers from MITE-flanking sequences. We observed 14 cases of polymorphic insertions into introns $(8$ cases), exons ( 2 cases, upstream or downstream to predicted coding sequence - UTR regions) or adjacent (4 cases, up to $1 \mathrm{~kb}$ upstream/downstream) to genes among emmer wheat accessions (Table 3 and Fig. 5), while 8 cases were population-unique insertions (e.g., an insertion of an Aison element 400 bp upstream of a predicted gene encoding a sterol-dependent membrane protein, in all accessions collected from Mt. Hermon only, Fig. 6a), or population-specific insertions (e.g.: an insertion of a Minos element in exon 2 of an uncharacterized protein in accessions from Amiad and Tabgha only, Fig. 6b; an insertion of Eos in an exon of a nuclear-localized, ATP binding, transcription regulation gene in all accessions of Mt. Amasa and Mt. Hermon populations, and some accessions of Amiad and Jaba, but not in Tabgha, Fig. 6c; and an insertion of Thalos in intron 1 of the ER membrane protein, transferring acyl gene present in all accessions of Mt. Amasa, Amiad and Mt. Hermon, and absent from one accession of Tabgha and some accessions of Jaba, Fig. 6d). Detailed analysis of the 14 polymorphic insertions, including the exact location of the TE insertion and the insertional patterns in wild emmer wheat accessions is presented in Table 3. In addition, site-specific PCR analysis is also shown in Additional file 2: Figure S8. Note that two polymorphic insertions of Thalos and Eos were found in introns of the same gene (Table 3, Fig. $5 \mathrm{~g}$ ). Our data indicate that insertions of MITEs into or adjacent to protein-coding genes cause population-specific allelic variation in wild emmer wheat. In 13 of the 14 cases, the polymorphic MITE insertions were present only in one of the two subgenomes (6 insertions in AA subgenome and 7 insertions in BB subgenomes) of emmer wheat, while only one polymorphic insertion was present in both subgenomes (Table 3). 


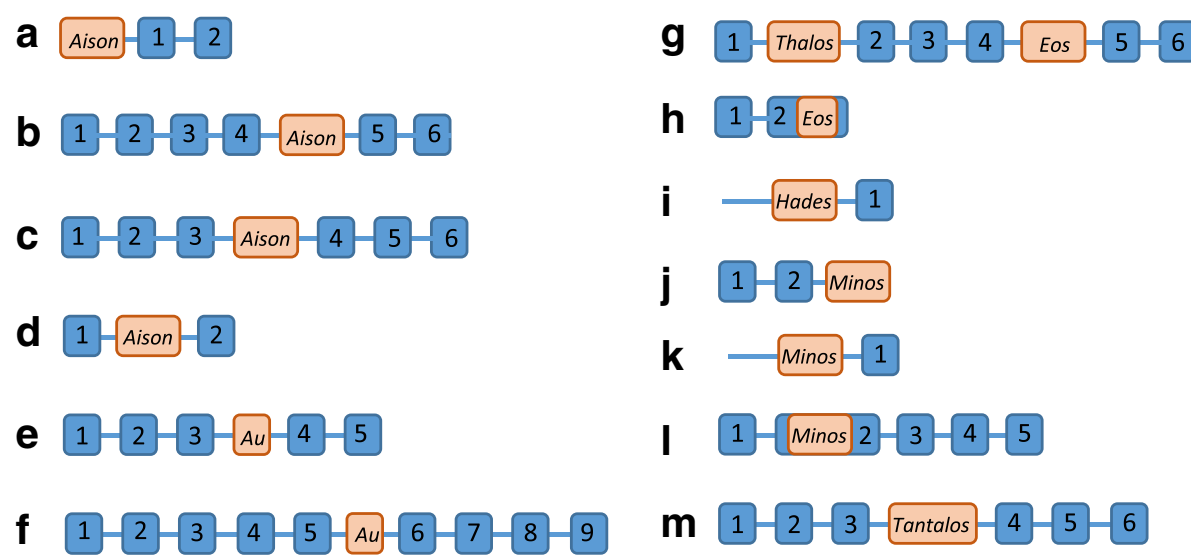

Fig. 5 Schematic representation of the structure of 13 genes associated with 14 polymorphic TEs insertions. Blue boxes with numbers noted on them indicate exons, brown boxes with a TE family noted on them indicate TE insertions. a) TRIUR3_24471, b) TRIUR3_29094, c) Traes_2BS_2453C5E6B, d) Traes_7BL_2E24532BD, e) FJ640556.1, f) Traes_1BL_DD7D021A7, g) TRIUR3_22200, h) Traes_4BS_AAE1439D4, i) GU817319.1, j) Traes_3AS_94E185821, k) Traes_3AS_2755E639C, l) Traes_7AL_OD3EF0026, $\mathbf{m}$ ) Traes_3B_5DEF2D3F1

\section{Expression analysis of genes that harbor polymorphic MITE insertions}

The expression of genes might be associated with TE insertions [22, 39]. As such, the observed allelic variation in protein-coding genes caused by TE insertion in wild emmer wheat might impact the expression of those genes. Note that most of the genes that were found to harbor polymorphic MITE insertions were not studied before in wheat. In addition, we found that the genes are highly conserved (over 99\% similarity at the predicted exons sequences) between the two subgenomes (AA and $\mathrm{BB})$ of emmer wheat. Thus, because the polymorphic MITE insertions were found in only one of the subgenomes in most cases (13 out of 14; Table 3 ), it was challenging to test the expression of those genes in a genome-specific manner. To this end, we have successfully examined the expression of five genes (Ensembl or gene bank accessions: Traes_7BL_2E24532BD, FJ64055 6.1, Traes_1BL_DD7D021A7, Traes_3AS_94E185821, Traes_3B_5DEF2D3F, Table 3) in young leaves of all tested wild emmer wheat accessions from the five populations. Real-time RT-PCR was performed using CDNA prepared from RNA extracted from young leaves of wild emmer wheat accessions. Primers were designed from exon-exon junctions to ensure that there are no artifacts from genomic DNA amplifications, and in all cases, the primer efficiency was 100\% (Additional file 1: Table S4, Additional file 2: Figure S9). Thus, the relative expression levels of the five genes were tested in 3-9 accessions from each one of the five wild emmer wheat populations. Note that in order to measure standard errors, the RT-PCR experiments were done in triplicates, and the expression levels (relative to the normalized gene, Actin) of all accessions were presented in the graph by comparing their expression levels to a reference (accessions T1 or T2), whose expression level was set as 1 . Interestingly, all five genes showed significant differences in their expression levels among the different accessions of emmer wheat (Fig. 7). The expression levels of Traes_3AS_94E185821, a gene that encodes a predicted calcium-ion binding protein ranged between 0.3 fold (the expression of T2 accession was set as 1) in some accessions up to 2 fold in others (Fig. 7a), where the lower expression levels were observed in the accessions from Mt. Hermon and Mt. Amasa. The expression levels of FJ640556.1, a gene encoding for AIP2.2 - ABI3 (abscisic acid-insensitive 3)-interacting protein, ranged between 0.3 and 2 fold (the expression of $\mathrm{T} 1$ accession was set as 1) in the various accessions (Fig. 7b). The expression levels of Traes_3B_5DEF2D3F1, a gene encoding for a predicted basic helixloop-helix transcription factor ranged between 0.5 and 1.8 fold (the expression of T1 accession was set as 1) in the various accessions (Fig. 7c). The expression levels of Traes_7BL_2E24532BD, a gene encoding for a predicted RNA binding, ribosomal protein ranged between 0.8 and 7.5 fold (the expression of $\mathrm{T} 1$ accession was set as 1 ) in the various accessions (Fig. $7 \mathrm{~d}$ ). Finally, the expression levels of Traes_1BL_DD7D021A7, a gene encoding for a predicted Ubiquitin-protein ligase ranged between 0.2 and 1.7 fold (the expression of $\mathrm{T} 1$ accession was set as 1 ) in the various accessions (Fig. 7e).

\section{Discussion}

One of the consequences of wheat domestication and breeding programs is the loss of genetic diversity in commercial wheat cultivars [3, 40-42]. There are huge efforts in recent decades to restore genetic diversity to modern wheat cultivars from wild emmer wheat, the wild progenitor of all domesticated wheat species (the 


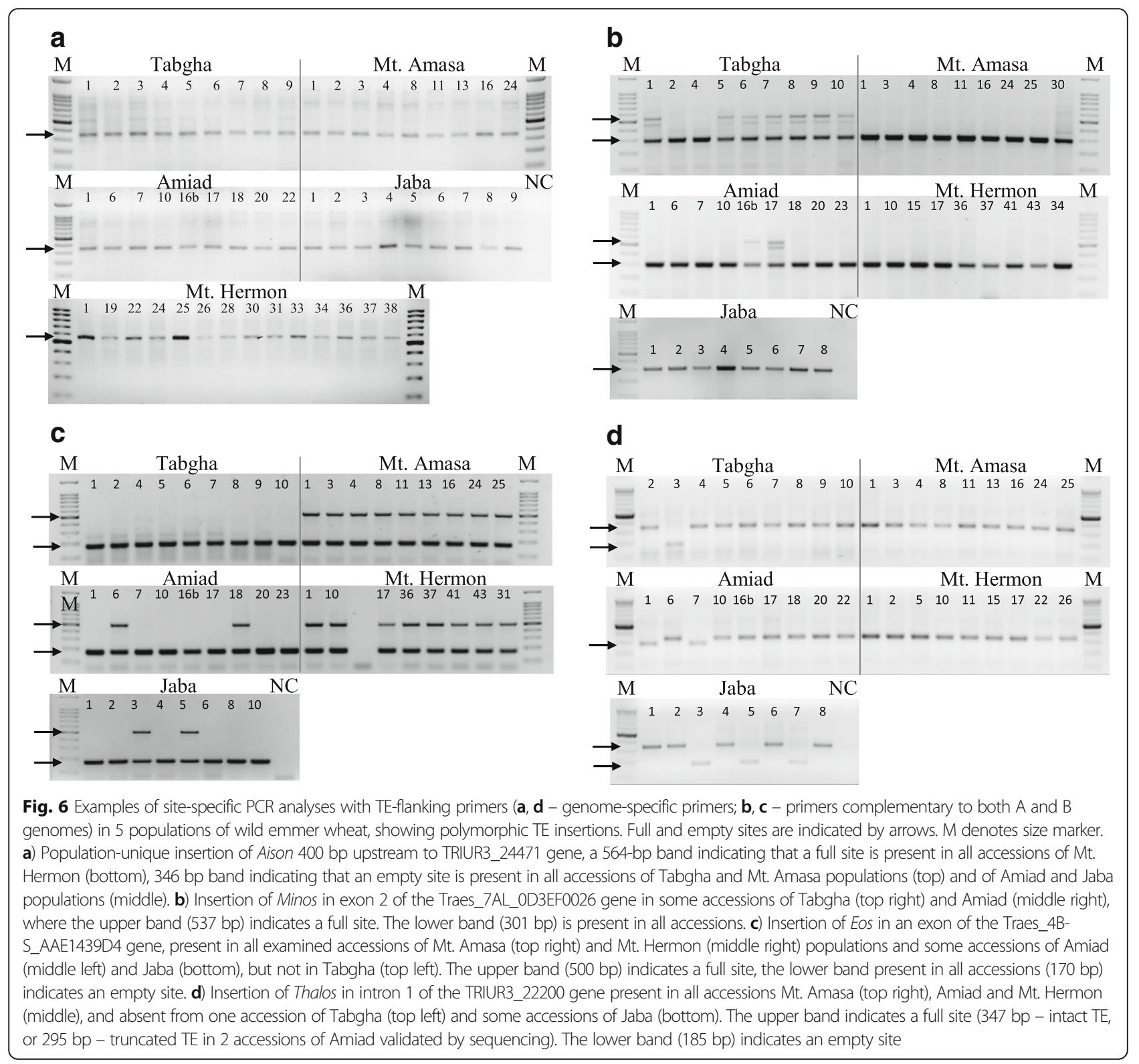

mother of wheat). The potential of wild emmer as a source of genes for biotic and abiotic stress tolerance has been widely recognized [43-45]. While many studies have been carried out on the phenotypic and genetic variations in natural populations of wild emmer wheat, almost nothing is known about the genome dynamics of wild emmer wheat in different climate conditions.

In this study, we have performed detailed analyses of TE dynamics in natural habitats of wild emmer wheat accessions, including: copy number variation, insertional patterns, allelic variation in protein-coding genes caused by TEs, and the impact of populationunique/specific TE insertions on gene expression. We found significant variation of the copy numbers of 12
TE families representing both TE classes (DNA and RNA elements). In addition, we found populationunique insertional patterns of TEs based on the phylogenetic analysis of six MITE families in the 50 accessions collected from five isolated geographical sites. About $18 \%$ of the analyzed 557 MITE insertions were considered population-specific and about $6 \%$ of the MITE insertions were population unique. Some of those population-specific/unique insertions were inserted into introns or exons of protein-coding genes and caused allelic variation in the wild emmer wheat. In accordance, we have validated the expression of some protein-coding genes that harbor polymorphic MITE insertions in wild emmer wheat accessions and differential expression was seen. 

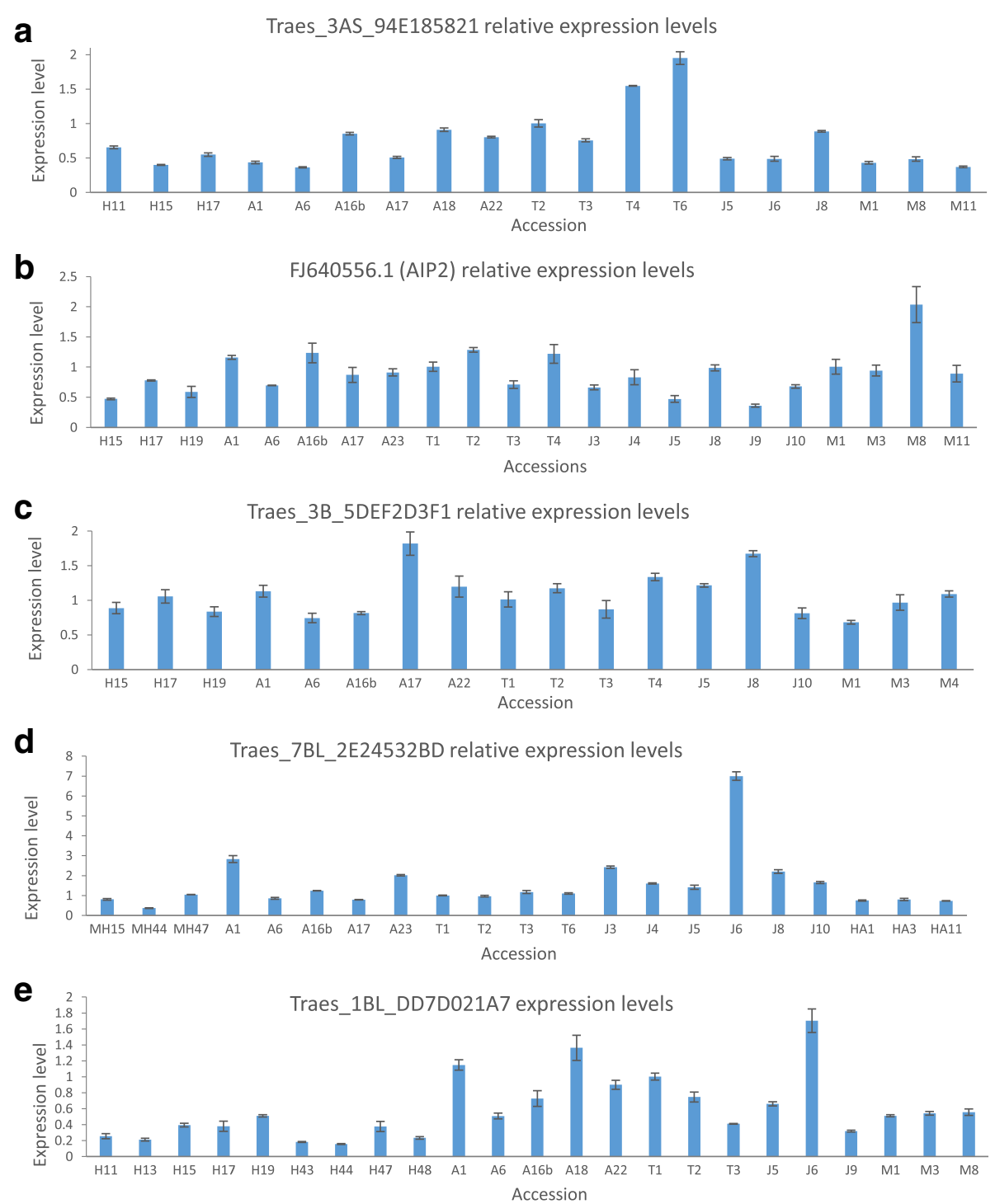

Fig. 7 Relative expression levels of 5 genes in young leaves of wild emmer wheat from 5 populations ( $\mathrm{H}-\mathrm{Mt}$. Hermon, A - Amiad, T - Tabgha, J - Jaba, M - Mt. Amasa). Error bars represent standard deviations of 3 replicates in RT-PCR reactions. a) Traes_3AS_94E185821; b) FJ640556.1 (AIP2); c) Traes_3B_5DEF2D3F1; d) Traes_7BL_2E24532B; e) Traes_1BL_DD7D021A7. Expression levels of each gene in each accession are shown relative to accession $\mathrm{T} 2$ in panel $\mathrm{a}$, and accession $\mathrm{T} 1$ in panels b-e

\section{Genetic polymorphism and TE dynamics}

In order to evaluate the contribution of TEs to the genetic variation in natural populations of wild emmer wheat we estimated the overall level of genetic polymorphism in wild emmer populations using TD [33, 46], an unbiased and a reliable technique (Fig. 3). It is important to note that although in some cases the common garden conditions would be different from the natural conditions for some populations, but the conditions used in the greenhouse are not stressful to any of the populations, therefore they should not affect the veracity of the conclusions.
Overall, 557 MITE insertions of 6 MITE families were analyzed in this study in all accessions of the five populations. The insertional polymorphisms varied dramatically between the MITE families, where some MITE families showed a relatively low polymorphism level (such as Minos, average polymorphism level of $38.6 \%$, Table 2), and other families showed very high polymorphism level (such as Aison, average polymorphism level of $91.9 \%$, Table 2). The TD data indicate that TE dynamics might largely contribute to the genetic biodiversity in emmer wheat because TEs comprise over $80 \%$ of the wheat genome 
and therefore might be responsible for most genetic variation between accessions.

Phylogenetic trees based on TD data significantly $(p<0.05)$ clustered the wild emmer wheat accessions based on geographical location (Fig. 4 and Additional file 2: Figures S3-S7).

The TD data support previous findings of populationspecific genetic clustering $[4,12]$. The significant separation between accessions within populations also correspond with previous reports regarding micro-scale adaptive genetic differentiation [14, 47], and limited gene flow between predominantly self-pollinating plants [48] is likely to preserve existing genetic patterns.

Do the significant population-unique insertional patterns observed here indicate MITE activity in natural populations of wild emmer wheat? Assuming that each population starts from a certain number of individuals with a certain set of genotypes changing under selection and other evolutionary constrains, and provided all examined MITEs existed before the populations were established, a certain number and pattern of each MITE was linked to each of the initial genotypes. Therefore, TE insertional polymorphism alone might not be sufficient evidence of transposon activity in natural populations, because this may be explained by founder effect. In addition, it is difficult to point to the exact reasons for differential MITE activity, because they are nonautonomous elements requiring suitable active autonomous DNA elements in order to be mobilized, and those are still unknown in wheat. It was previously reported that TEs can be mobilized by stress conditions, and such conditions could occur simultaneously or at different times in different habitats.

Differential proliferation of TEs in wild emmer wheat populations might lead to huge copy number variation among accessions. Here we observed significant copy number variation of 12 TE families, including DNA and RNA elements (Table 1), in the 50 accessions collected from the five isolated geographical sites (Fig. 1 and Fig. 3). The question, whether those significant differences in TE copy number might affect genome size, was considered and tested by measuring the genome size of wild emmer wheat accessions collected from four populations, using the Fluorescence-Activated Cell Sorting (FACS) technique (see details in Additional file 2: Figure S10). The FACS data revealed a similar genome size for accessions collected from different populations, indicating that the variation in TE copy number did not massively affect the genome size of wild emmer wheat. One explanation is that the copy number variation observed here was in all cases TE family-specific, meaning that, for example, while the copy number of one TE family was relatively high in a specific population, another TE family showed a relatively low copy number in the same population.

\section{Allelic variation of genes harboring MITEs}

The TD data motivated us to search for populationspecific/unique insertions in protein-coding genes and we observed many of those cases (Figs. 6 and 7, and Additional file 2: Figure S8). Out of the 14 examined polymorphic insertions: 8 were found in introns, 3 upstream to genes in distances between $22 \mathrm{bp}$ to $960 \mathrm{bp}$, one insertion was $2 \mathrm{bp}$ downstream to a gene, and two insertions occurred within exons but upstream or downstream to predicted coding sequences (Table 3). These insertions can possibly be neutral or can alter gene function in different ways depending on their locations: TEs within introns can possibly interfere with the splicing process, insertions upstream or downstream to a gene can affect regulatory sequences, and insertions into UTR regions do not change the coding sequence but can possibly affect transcript stability. In order to examine whether each particular insertion alters expression levels, genome-specific expression analysis will be needed, because the insertional polymorphism exists in one of the two genomes, and the expression can occur from one or both genomes. Here we showed that protein-coding genes harboring polymorphic MITE insertions in wild emmer wheat had different expression levels among wild emmer wheat accessions (Fig. 7). It is still not fully clear whether the population-unique/specific polymorphic TE insertion on those genes impacts their expression and whether it is correlated with any adaptive value.

\section{Conclusions}

We show here novel data on massive TE dynamics in natural populations of a very important organism - wild emmer wheat (the mother of all wheats). We showed that TE dynamics might affect genome structure and expression in a population-specific/unique manner. This data sheds lights on the role of TEs in shaping the genome of natural plant populations in different climate conditions, especially because TEs are the single largest component of most land plant genomes [49].

\section{Additional files}

Additional file 1: Table S1. Primer sequences used for copy number variation analysis of TEs by real-time qPCR. Table S2. Adaptor and primer sequences used in Transposon Display (TD). Table S3. Primer sequences for site-specific PCR. Table S4. Primer sequences for site-specific PCR. (DOCX $28 \mathrm{~kb})$

Additional file 2: Figure S1. Quantification of DNA elements in accessions of 5 wild emmer wheat population. Figure S2. Relative quantities of long TEs in 5 wild emmer wheat populations. Figure S3. Phylogenetic tree generated by hierarchical agglomerative clustering based on 99 TD bands of Aison. Figure S4. Phylogenetic tree generated by hierarchical agglomerative clustering on 70 TD bands of Fortuna. Figure S5. Phylogenetic tree generated by hierarchical agglomerative clustering based on 92 TD bands of Oleus. Figure S6. Phylogenetic tree generated by hierarchical agglomerative 
clustering based on 116 TD bands of Tantalos. Figure S7. Phylogenetic tree generated by hierarchical agglomerative clustering based on 92 TD bands of Eos. Figure S8. Site-specific PCR with TE-flanking primer. Figure S9. A qPCR standard curve produced using primers for Traes_1BL_DD7D021A7 gene. Figure S10. Genome size (pg) of wild emmer wheat from 4 populations. (PDF $1237 \mathrm{~kb})$

\section{Abbreviations}

AFLP: Amplified fragment length polymorphism; BLAST: Basic Local Alignment; LTR: Long terminal repeat; MITE: Inverted-repeat transposable element; NCBI: National center for biotechnology information; SINE: Small interspersed nuclear element; TD: Transposon display; TE: Transposable element; TRIM: Terminal inverted repeat in miniature

\section{Acknowledgments}

We want to thank the Lieberman Germplasm Bank, Institute for Cereal Crops Improvement, Tel-Aviv University and the Wild Cereals gene bank (WCGB) Institute of Evolution, University of Haifa, Dr. Sergei Volis and Prof. Eviatar Nevo for providing the seed material.

This work was supported by a grant from the Israel Science Foundation (grant \# 322/15) to K. K.

\section{Funding}

This work was supported by a grant from the Israel Science Foundation (grant \# 322/15) to K. K.

\section{Availability of data and materials}

The binary and resemblance matrices used to construct phylogenetic trees (Fig. 4, Additional file 2: Figures S3-S7) are available at TreeBase: http://purl.org/ phylo/treebase/phylows/study/TB2:S21562?x-access-code=8a8c38e26e942724 c3db08d9b3d69c1b\&format=htm

Wild emmer wheat seeds are available in the Wild Cereals gene bank (WCGB) - Institute of Evolution, University of Haifa (Tabgha and Jaba populations), and in the Lieberman Germplasm Bank, Institute for Cereal Crops Improvement, Tel-Aviv University (Mt. Hermon, Amiad and Mt. Amasa populations)

\section{Authors' contributions}

KD: data generation, data analysis, manuscript preparation. DK: data generation. BY: data generation, data analysis. VK: data generation. KK: data analysis, manuscript preparation. All authors read and approved the final manuscript.

\section{Ethics approval and consent to participate} Not applicable.

\section{Consent for publication}

Not applicable.

\section{Competing interests}

The authors declare that they have no competing interests.

\section{Publisher's Note}

Springer Nature remains neutral with regard to jurisdictional claims in published maps and institutional affiliations.

Received: 4 December 2016 Accepted: 17 October 2017

Published online: 27 October 2017

\section{References}

1. Dvorak J, Akhunov ED. Tempos of gene locus deletions and duplications and their relationship to recombination rate during diploid and polyploid evolution in the Aegilops-Triticum alliance. Genetics. 2005;171(1):323-32

2. Huang S, Sirikhachornkit A, Su X, Faris J, Gill B, Haselkorn R, Gornicki P. Genes encoding plastid acetyl-CoA carboxylase and 3-phosphoglycerate kinase of the Triticum/Aegilops Complex and the evolutionary history of polyploid wheat. Proc Natl Acad Sci U S A. 2002;99(12):8133-8.

3. Luo MC, Yang ZL, You FM, Kawahara T, Waines JG, Dvorak J. The structure of wild and domesticated emmer wheat populations, gene flow between them, and the site of emmer domestication. Theor Appl Genet. 2007;114(6):947-59.
4. Nevo E, Beiles A. Genetic diversity of wild emmer wheat in Israel and Turkey : structure, evolution, and application in breeding. Theor Appl Genet. 1989;77(3):421-55.

5. Ozbek O, Millet E, Anikster Y, Arslan O, Feldman M. Comparison of the genetic structure of populations of wild emmer wheat, Triticum Turgidum Ssp. Dicoccoides, from Israel and Turkey revealed by AFLP analysis. Genet Resour Crop Evol. 2007;54(7):1587-98

6. Hillman G. Late Pleistocene changes in wild plant-foods available to huntergatherers of the northern fertile crescent: possible preludes to cereal cultivation. In: The origins and spread of agriculture and pastoralism in Eurasia. London: UCL Press; 1996. p. 159-203.

7. Bar-Yosef $\mathrm{O}$. On the nature of transitions: the middle to upper Palaeolithic and the Neolithic revolution. Camb Archaeol J. 1998:8(2):141-63.

8. Feldman M, Kislev ME. Domestication of emmer wheat and evolution of free-threshing tetraploid wheat. Israel J Plant Sci. 2007:55(3-4):207-21.

9. Volis $\mathrm{S}$, Song $\mathrm{M}$, Zhang $\mathrm{Y}-\mathrm{H}$, Shulgina I. Fine-scale spatial genetic structure in emmer wheat and the role of population range position. Evol Biol. 2014; 41(1):166-73.

10. Huang L, Sela H, Feng L, Chen Q, Krugman T, Yan J, Dubcovsky J, Fahima T. Distribution and haplotype diversity of WKS resistance genes in wild emmer wheat natural populations. Theor Appl Genet. 2016;129(5):921-34.

11. Krugman $T$, Chagué $V$, Peleg $Z$, Balzergue $S$, Just J, Korol AB, Nevo E, Saranga $Y$, Chalhoub B, Fahima T. Multilevel regulation and signalling processes associated with adaptation to terminal drought in wild emmer wheat. Funct Integr Genomics. 2010;10(2):167-86.

12. Joshi CP, Nguyen HT. Application of the random amplified polymorphic DNA technique for the detection of polymorphism among wild and cultivated tetraploid wheats. Genome. 1993;36(3):602-9.

13. Li CY, Fahima T, Beiles A, Korol BA, Nevo E. Microclimatic stress and adaptive DNA differentiation in wild emmer wheat, Triticum Dicoccoides. Theor Appl Genet. 1999;98(6):873-83.

14. Li Y, Fahima T, Korol AB, Peng J, Röder MS, Kirzhner V, Beiles A, Nevo E. Microsatellite diversity correlated with ecological-edaphic and genetic factors in three microsites of wild emmer wheat in North Israel. Mol Biol Evol. 2000;17(6):851-62.

15. Volis S, Ormanbekova D, Yermekbayev K, Song M, Shulgina I. The conservation value of peripheral populations and a relationship between quantitative trait and molecular variation. Evol Biol. 2016;43(1):26-36.

16. Casacuberta JM, Santiago N. Plant LTR-retrotransposons and MITEs: control of transposition and impact on the evolution of plant genes and genomes. Gene. 2003;311:1-11.

17. Daron J, Glover N, Pingault $L$, Theil S, Jamilloux V, Paux E, Barbe V, Mangenot S, Alberti A, Wincker $P$, et al. Organization and evolution of transposable elements along the bread wheat chromosome 3B. Genome Biol. 2014:15(12):546.

18. (IWGSC) IWGSC. A chromosome-based draft sequence of the hexaploid bread wheat (Triticum Aestivum) genome. Science. 2014;345(6194):1251788.

19. Wicker T, Sabot F, Hua-Van A, Bennetzen JL, Capy P, Chalhoub B, Flavell A Leroy $\mathrm{P}$, Morgante $\mathrm{M}$, Panaud $\mathrm{O}$, et al. A unified classification system for eukaryotic transposable elements. Nat Rev Genet. 2007;8(12):973-82.

20. Vitte C, Panaud O. LTR retrotransposons and flowering plant genome size: emergence of the increase/decrease model. Cytogenet Genome Res. 2005:110(1-4):91-107.

21. Park SJ, Kim YH, Lee SR, Choe SH, Kim MJ, Kim SU, Kim JS, Sim BW, Song BS, Jeong $\mathrm{KJ}$, et al. Gain of a new exon by a lineage-specific Alu elementintegration event in the BCS1L gene during primate evolution. Mol Cells. 2015:38(11):950-8.

22. Feschotte C, Pritham EJ. DNA transposons and the evolution of eukaryotic genomes. Annu Rev Genet. 2007;41:331-68.

23. Lippman Z, Gendrel AV, Black M, Vaughn MW, Dedhia N, McCombie WR, Lavine K, Mittal V, May B, Kasschau KD, et al. Role of transposable elements in heterochromatin and epigenetic control. Nature. 2004;430(6998):471-6.

24. Venetsky A, Levy-Zamir A, Khasdan V, Domb K, Kashkush K. Structure and extent of DNA methylation-based epigenetic variation in wild emmer wheat (T. Turgidum Ssp. Dicoccoides) populations. BMC Plant Biol. 2015;15:200.

25. Yan L, Loukoianov A, Tranquilli G, Helquera M, Fahima T, Dubcovsky J. Positional cloning of the wheat vernalization gene VRN1. Proc Natl Acad Sc U S A. 2003:100(10):6263-8.

26. Kraitshtein Z, Yaakov B, Khasdan V, Kashkush K. Genetic and epigenetic dynamics of a retrotransposon after allopolyploidization of wheat. Genetics. 2010;186(3):801-U889. 
27. Yaakov B, Ben-David S, Kashkush K. Genome-wide analysis of stowaway-like MITEs in wheat reveals high sequence conservation, gene association, and genomic diversification. Plant Physiol. 2013;161(1):486-96.

28. Yaakov B, Meyer K, Ben-David S, Kashkush K. Copy number variation of transposable elements in Triticum-Aegilops genus suggests evolutionary and revolutionary dynamics following allopolyploidization. Plant Cell Rep. 2013;32(10):1615-24.

29. Livak KJ, Schmittgen TD. Analysis of relative gene expression data using real-time quantitative PCR and the 2(-Delta Delta C(T)) method. Methods. 2001;25(4):402-8.

30. Kersey PJ, Allen JE, Armean I, Boddu S, Bolt BJ, Carvalho-Silva D, Christensen M, Davis P, Falin LJ, Grabmueller C, et al. Ensembl Genomes 2016: more genomes, more complexity. Nucleic Acids Res. 2016;44(D1):D574-80.

31. Yang G, Hall TC. MAK, a computational tool kit for automated MITE analysis. Nucleic Acids Res. 2003;31(13):3659-65.

32. Inc. D: Dell Statistica (data analysis software system), version 12. software. dell.com. In.; 2015

33. Van den Broeck D, Maes T, Sauer M, Zethof J, De Keukeleire P, D'hauw M, Van Montagu M, Gerats T. Transposon display identifies individual transposable elements in high copy number lines. Plant J. 1998;13(1):121-9.

34. Vandenbussche M, Zethof J, Gerats T. Transposon display: a versatile method for transposon tagging. Methods Mol Biol. 2013;1057:239-50.

35. Altschul SF, Gish W, Miller W, Myers EW, Lipman DJ. Basic local alignment search tool. J Mol Biol. 1990;215(3):403-10.

36. Clarke KR. Non-parametric multivariate analyses of changes in community structure. Aust J Ecol. 1993;18(1):117-43.

37. Hosid E, Brodsky L, Kalendar R, Raskina O, Belyayev A. Diversity of long terminal repeat retrotransposon genome distribution in natural populations of the wild diploid wheat Aegilops Speltoides. Genetics. 2012;190(1):263-74.

38. Yaakov B, Kashkush K. Mobilization of stowaway-like MITEs in newly formed allohexaploid wheat species. Plant Mol Biol. 2012;80(4-5):419-27.

39. Hirsch CD, Springer NM. Transposable element influences on gene expression in plants. Biochimica et Biophysica Acta (BBA)-Gene Regulatory Mechanisms. 2017;1860(1):157-65

40. Dvorak J, Luo MC, Akhunov ED. NI Vavilov's theory of centres of diversity in the light of current understanding of wheat diversity, domestication and evolution. Czech J Genet Plant Breed. 2011:47:S20-7.

41. Haudry A, Cenci A, Ravel C, Bataillon T, Brunel D, Poncet C, Hochu I, Poirier S, Santoni S, Glémin S, et al. Grinding up wheat: a massive loss of nucleotide diversity since domestication. Mol Biol Evol. 2007;24(7):1506-17.

42. Akhunov ED, Akhunova AR, Anderson OD, Anderson JA, Blake N, Clegg MT, Coleman-Derr D, Conley EJ, Crossman CC, Deal KR, et al. Nucleotide diversity maps reveal variation in diversity among wheat genomes and chromosomes. BMC Genomics. 2010;11:702.

43. Grama A, Gerechter-Amitai ZK. Inheritance of resistance to stripe rust (Puccinia striiformis) in crosses between wild emmer (Triticum Dicoccoides) and cultivated tetraploid and hexaploid wheats. II. Triticum Aestivum. Euphytica. 1974:23(2):393-8.

44. Peleg Z, Fahima T, Abbo S, Krugman T, Nevo E, Yakir D, Saranga Y. Genetic diversity for drought resistance in wild emmer wheat and its ecogeographical associations. Plant Cell Environ. 2005;28(2):176-91.

45. Fu D, Uauy C, Distelfeld A, Blechl A, Epstein L, Chen X, Sela H, Fahima T, Dubcovsky J. A kinase-START gene confers temperature-dependent resistance to wheat stripe rust. Science. 2009;323(5919):1357-60.

46. Zhang X, Feschotte C, Zhang Q, Jiang N, Eggleston WB, Wessler SR. P instability factor: an active maize transposon system associated with the amplification of tourist-like MITEs and a new superfamily of transposases. Proc Natl Acad Sci. 2001;98(22):12572-7.

47. Li YC, Röder MS, Fahima T, Kirzhner VM, Beiles A, Korol AB, Nevo E. Climatic effects on microsatellite diversity in wild emmer wheat (Triticum Dicoccoides) at the Yehudiyya microsite, Israel. Heredity (Edinb). 2002;89(2):127-32.

48. Golenberg EM. Outcrossing rates and their relationship to phenology in Triticum Dicoccoides. Theor Appl Genet. 1988;75(6):937-44.

49. Feschotte C, Jiang N, Wessler SR. Plant transposable elements: where genetics meets genomics. Nat Rev Genet. 2002;3(5):329-41.

\section{Submit your next manuscript to BioMed Central and we will help you at every step:}

- We accept pre-submission inquiries

- Our selector tool helps you to find the most relevant journal

- We provide round the clock customer support

- Convenient online submission

- Thorough peer review

- Inclusion in PubMed and all major indexing services

- Maximum visibility for your research

Submit your manuscript at www.biomedcentral.com/submit
) Biomed Central 